\title{
Exposure Route of Administration
}

National Cancer Institute

\section{Source}

National Cancer Institute. Exposure Route of Administration. NCI Thesaurus. Code C83121.

Designation of the part of the body through which the exposure is introduced. 